\title{
Assessment of Sexual Risk Behaviours among Young People Patronizing Alcoholic Beverage Selling Outlets in Makurdi, Benue State, Nigeria Audu O, ${ }^{1^{*}}$, Ogbeyi GO ${ }^{1}$, Omole VN ${ }^{2}$, Joshua IA ${ }^{2}$, Gobir AA ${ }^{3}$, Anejo-Okopi $\mathrm{JA}^{4}$
}

${ }^{1}$ Department of Epidemiology and Community Health, College of Health Sciences, Benue State University, Makurdi, Nigeria.

${ }^{2}$ Department of Community Medicine Kaduna State University Kaduna Nigeria ${ }^{3}$ Department of Community Medicine, Ahmadu Bello University, Zaria, Kaduna State, Nigeria.

${ }^{4}$ Department of Microbiology, University of Jos, Jos, Nigeria.

Corresponding author: Audu, Onyemocho.

E-mail: audeeony@yahoo.com

\begin{abstract}
Background: Young people constitute 16\% of the global population and in Benue State Nigeria, majority of them take alcohol which is one of the identified drivers of high risk sexual behaviours. However, intervention strategies at the pubs where alcoholic beverages are sold remain peripheral. This study assessed the sexual risk taking behaviours among young people who patronized alcoholic beverage selling outlets in Makurdi, the Benue State capital.
\end{abstract}

Methods: A community based cross-sectional study using interviewer administered questionnaire was conducted among 273 young people sampled from 4 night clubs and 28 bars. Logistic regression analysis was conducted to determine the relationship between alcohol use and risky sexual practices with statistical significance set at $p=0.05$

Results: Seventy-four percent of the respondents had history of sexual intercourse with mean age of $18.2( \pm 3.0)$ years at sexual debut. Ninety eight (48.5\%) had sexual intercourse within a week prior to the study, $73.8 \%$ took alcohol before the last sexual intercourse and the practice corroborates a cycle of sexual risk behaviour which include: heterosexual (100\%), onenight stand (62.2\%), sex without condoms (48.0\%), oral sex (42.6\%), sex in exchange for money (32.7\%), anal sex (26.5\%) and group sex (9.2\%). Those who take alcohol are 8.5 times at higher risk of engaging in anal sex $\{(O R-8.464)(95 \% C I=2.919-24.53)(p=0.0433)\}$.

Conclusion: Policymakers working on risk taking behaviour intervention should consider night clubs and other drinking establishments in order to mitigate the effects of diseases transmitted through high risk sexual behavior among young people.

Keywords: Alcohol Intake, Risky Behaviour, Disease

\section{Introduction}

Young people (10-24 years) constitute about $16 \%$ of the global population and
Benue State Nigeria, like other parts of the world, has a high proportion of adolescents (10-19 years) and young people. ${ }^{1,2}$ As these 
population groups go through the demographic transition, they are faced with challenges of peer group pressure, low infection risk perception and low selfesteem. These make adolescents and young people more vulnerable to health risk behaviours like unprotected sex, physical inactivity, use of tobacco, alcohol and illicit drugs as compared to other groups $^{3-5}$

Alcohol has been an integral part of most human cultures for years; nevertheless, the consumption carries risk of adverse health and social consequences which are related to its intoxicating and dependenceproducing properties. ${ }^{6,7}$ Alcohol use has been reported as the largest single contributor of risks to health in young people in both low and high income countries. $^{7,8}$ The intake has been identified as a driver of Human Immunodefficiency Virus (HIV) infection in Benue State and the young people are not left out., ${ }^{91}$ In 2016, about 2.1 million people aged between 10 and 24 years were living with HIV and 260,000 became newly infected with the virus. ${ }^{11}$ In 2018, Benue State had an estimated 190,913 People Living with HIV/AIDS (PLHIVs) accounting for a prevalence of $4.9 \%$, the second highest in Nigeria. There is considerable variation in the prevalence across the Local Government Areas (LGAs) of Benue State with Ado LGA having the least (1.5\%), Ukum having the highest $(6.1 \%)$ and Makurdi, the State headquarter having $4.5 \% .^{12}$

To accelerate efforts towards ending the HIV epidemic, the Joint United Nations Programme on HIV/AIDS (UNAIDS) released the 95-95-95 targets for 2030. In this strategy, $95 \%$ of PLHIV are expected to know their HIV status; $95 \%$ of people who know their status are to be on antiretroviral therapy, and $95 \%$ of people on treatment are to have suppressed viral loads. ${ }^{13-15}$ This life-cycle approach to HIV ensures best solutions to a zero transmission level of HIV amongst all population groups throughout their lifetime. However, intervention strategies at bars and nightclubs where alcoholic beverages are sold remain peripheral in response to HIV transmission. ${ }^{15}$ Even though it is generally recognized that alcohol is a strong driver of high risk sexual behaviour, the actual sexual behaviour of young people who patronize drinking outlets in Makurdi remains unknown. Against this background, we conducted this study to assess the sexual risk taking behaviours among young people who patronized alcoholic beverage selling outlets in Makurdi, north central, Nigeria.

\section{Study Area}

\section{Methods}

Benue is one of the 36 States located in the North Central geo-political zone of Nigeria with an estimated population of 6,381,985 (projected from 2006 National Census). It shares boundaries in the north with Nasarawa State, in the east with Taraba State, in the south with Cross River and Ebonyi States and in the west with Enugu and Kogi States. The largest town in the State is Makurdi which serves as the State capital and also as the headquarters of Makurdi Local Government Area (LGA). Makurdi LGA has eleven council wards, namely Mbalagh, Agan, North Bank I, North Bank II, Fidi, Wailomayo, Baa, Mordern Market, Ankpa/Wadata, Clerk Market and Central/South Mission wards. Almost every street in the council wards has a beer palour where alcoholic beverages are sold. At the time of this study, there were five functional night clubs in Makurdi town. The patronage of the bars was on daily basis but more in the evening while the clubs are mainly on Wednesdays, Fridays and Saturdays.

Study design, sample size determination 


\section{and study population}

A cross sectional descriptive study design was employed for the study which took place between $12^{\text {th }}$ and $28^{\text {th }}$ April, 2019. The study population consisted of all young people patronizing beer palours and night clubs in Makurdi town. In this study the WHO definition of young people (1024 years) was considered. ${ }^{8}$ With prevalence of $80 \%$ of young adults reported to be engaged in unprotected/risky sex following alcohol consumption in a previous study, ${ }^{6}$ and $5 \%$ degree of precision at $95 \%$ confidence interval, a minimum sample size of 246 was arrived at using the formula $n=z^{2} p(1-$ $\mathrm{p}) / \mathrm{d}^{2} .{ }^{16}$ Considering non-response rate of $10 \%$ the calculated sample size was adjusted to 273 .

\section{Sampling Technique}

A Multistage sampling technique was used for the study. Stage 1 was selection of night clubs and beer palours. In this stage, an ethnographic survey of the major hubs in Makurdi LGA was carried out after which 4 night clubs and 28 beer parlours with the highest patronage were selected from a total of 43 through convenience sampling across the 11 council wards. Stage 2 was selection of respondents. In this stage, equal allocation of 6 persons per night club and at least 5 persons per beer palour was done before the minimum sample size of 273 was arrived at.

\section{Data collection}

A structured interviewer administered questionnaire was used to collect data and was administered by research assistants drawn from the Department of Epidemiology and Community Health, Benue State University Teaching Hospital Makurdi. For the night clubs, the questionnaire was administered on Wednesdays (called the lady's night), Fridays and Saturdays while the questionnaire for the beer parlours was administered between 4.00-6.30 pm daily.
The purpose of the research was explained to each of the respondents and their consent was sought before the administration of the questionnaire. Information was obtained on sociodemographic profile, knowledge of alcohol as correlate to HIV infection, intake of alcohol, and practice of risky sexual behaviour. The research assistants were trained on the research protocol before data collection commenced. .

\section{Data analysis}

Data was analyzed using Staistical Package for Social Sciences (SPSS) version 23.0 and presented as tables and charts. Independent variables considered were the sociodemographic variables and intake of alcohol, while the outcome measures of interest included sexual intercourse without condom, casual sex with someone met at first instance, onenight stand, received/performed oral sex, sex in exchange for money, anal sex and group sex. Data collected were sorted, categorized, summarized and presented in frequency tables and charts. Chi square $(x 2)$ test was used to test the association between the independent variables and the main outcome variables of the study, with statistical significance set at $\mathrm{p}$-value of 0.05 . The linear relationship between the predictor variables and the outcome (criterion) variables was further performed to investigate the independent predictors that had significant association on the Chi square test by controlling for possible confounders.

\section{Results}

\section{Socio-demographic characteristics of} respondents

Their mean age was $22.5( \pm 1.5)$ years, with male to female ratio of $2.3: 1$. More than three quarters $(88.6 \%)$ were single and Christians constituted $85.7 \%$. The largest group $(46.9 \%)$ were in or had completed tertiary institutions, followed by secondary schools (29.7\%), primary 
schools $(6.6 \%)$ and $16.7 \%$ were school drop outs. Table 1

\section{Sexual activities of respondents}

Almost three quarters $(74.0 \%)$ of the respondents agreed to have had sexual intercourse in the

Past and the overall mean age at sexual debut was $18.2( \pm 3.0)$ years. Eighty-eight $(43.6 \%)$ had

2-3 lifetime sexual partners, 68(33.7\%) had four and above, while $46(22.8 \%)$ had a single sexual partner, with mean number of 3.6 partners $( \pm 2.6)$ for males and $2.9( \pm$ 1.9) for females. Ninety

eight $(48.5 \%)$ had sexual intercourse within the week before the study. Out of these $72(73.8 \%)$ had history of intake of alcohol before the sexual intercourse, while 26 $(26.2 \%)$ had no history of

intake of alcohol before sexual intercourse

\section{Sexual risk taking behaviour}

Figure 1 presents the high risk sexual behaviours practiced by the repondents who had sexual intercourse within a week before the study. The predominant high risk sexual practice was one-night stand $(62.2 \%)$, followed by non-use of condom
$(48.0 \%)$, received and performed oral sex (2.6\% , and $39.8 \%$ respectively), casual sex with someone met at first instance $(35.7 \%)$, sex in exchange for money $(32.7 \%)$, anal sex $(26.5 \%)$ and group sex $(9.2 \%)$.

Influence of alcohol intake on sexual risk taking behaviour

Table 3 shows that the respondents who took alcohol were 8.5 times at higher risk of engaging in anal sex compared to those who were not under the influence of alcohol $\{(\mathrm{OR}-8.464)(95 \% \mathrm{CI}=2.919-$ 24.53) $(\mathrm{p}=0.0433)\}$. Similarly, those who took alcohol were more likely to engage in heterosexual intercourse $\{(\mathrm{OR}-1.61)$ $(95 \% \mathrm{CI}=0.648-4.007)(\mathrm{p}=0.000)\}$. The risk of practice of group sexual intercourse was about 2.88 times higher among those who took alcohol compared to those who did not take alcohol, but the relationship was not statistically significant $\{(\mathrm{OR}-$ $2.889)(95 \% \mathrm{CI}=0.3795-21.99)(\mathrm{p}=0$. $0.2727)\}$. The relationship between onenight stand and intake of alcohol was also not statistically significant $\{(\mathrm{OR}-1.212)$ $(95 \% \mathrm{CI}=0.8178-1.797)(\mathrm{p}=0.3045)\}$.

Table 1: Sociodemographic characteristics of the respondents $(n=273)$

\begin{tabular}{ll}
\hline Characteristics & Frequency $(\%)$ \\
\hline Age (Years) & $27(9.9)$ \\
$<15$ & $100(36.6)$ \\
$15-19$ & $146(53.5)$ \\
$20-24$ & $22.5(+/-1.5)$ \\
Mean age (SD) & \\
Sex & $190(69.6)$ \\
Male & $83(30.4)$ \\
Female & $212(77.7)$ \\
Marital status & $61(22.3)$ \\
Single & \\
Married & $234(85.7)$ \\
Religion & $39(14.3)$ \\
Christian & \\
Muslim & $18(6.6)$ \\
Educational history & $81(29.7)$ \\
Primary & $128(46.9)$ \\
Secondary & $46(16.8)$ \\
Tertiary & \\
Drop out of school &
\end{tabular}


Table 2: Sexual activities of respondents by gender

\begin{tabular}{|c|c|c|c|}
\hline Variables & Total & Male & Female \\
\hline Ever had sexual intercourse & Freq. $(\%)$ & Freq. $(\%)$ & Freq. $(\%)$ \\
\hline Yes & $202(74.0)$ & $152(80.0)$ & $50(60.2)$ \\
\hline No & $71(26.0)$ & $38(20.0)$ & $33(39.8)$ \\
\hline Total & $273(100.0)$ & $190(100.0)$ & $83(100.0)$ \\
\hline \multicolumn{4}{|c|}{ Age at first sexual intercourse (years) } \\
\hline Mean Age (SD) & $18.2(3.0)$ & $18.2(3.0)$ & $18.2(2.9)$ \\
\hline$<15$ & $8(4.0)$ & $6(3.9)$ & $2(4.0)$ \\
\hline $15-19$ & $124(61.4)$ & $92(60.5)$ & $32(64.0)$ \\
\hline $20-24$ & $53(26.2)$ & $40(26.3)$ & $13(26.0)$ \\
\hline Not remember & $17(8.4)$ & $14(9.2)$ & $3(6.0)$ \\
\hline Total & $202(100.0)$ & $152(100.0)$ & $50(100.0)$ \\
\hline \multicolumn{4}{|c|}{ Number of Lifetime Sexual Partners } \\
\hline Mean (SD) & $3.4(2.4)$ & $3.6(2.6)$ & $2.9(1.9)$ \\
\hline 1 & $46(22.8)$ & $32(21.1)$ & $14(28.0)$ \\
\hline $2-3$ & $88(43.6)$ & $66(43.4)$ & $22(44.0)$ \\
\hline$\leq 4$ & $68(33.7)$ & $54(35.5)$ & $14(28.0)$ \\
\hline Total & $202(100.0)$ & $152(100.0)$ & $50(100.0)$ \\
\hline \multicolumn{4}{|c|}{ Sexual intercourse within a week prior to Study } \\
\hline Yes & $98(48.5)$ & $67(35.3)$ & $31(37.3)$ \\
\hline No & $104(51.5)$ & $123(64.7)$ & $52(62.7)$ \\
\hline Total & $202(100.0)$ & $190(100.0)$ & $83(100.0)$ \\
\hline \multicolumn{4}{|c|}{ Take alcohol before the last sexual intercourse $(n=98)$} \\
\hline Yes & $72(73.8)$ & $55(82.1)$ & $17(54.8)$ \\
\hline No & $26(26.2)$ & $12(17.9)$ & $14(45.2)$ \\
\hline Total & $98(100.0)$ & $67(100.0)$ & $31(100.0)$ \\
\hline
\end{tabular}

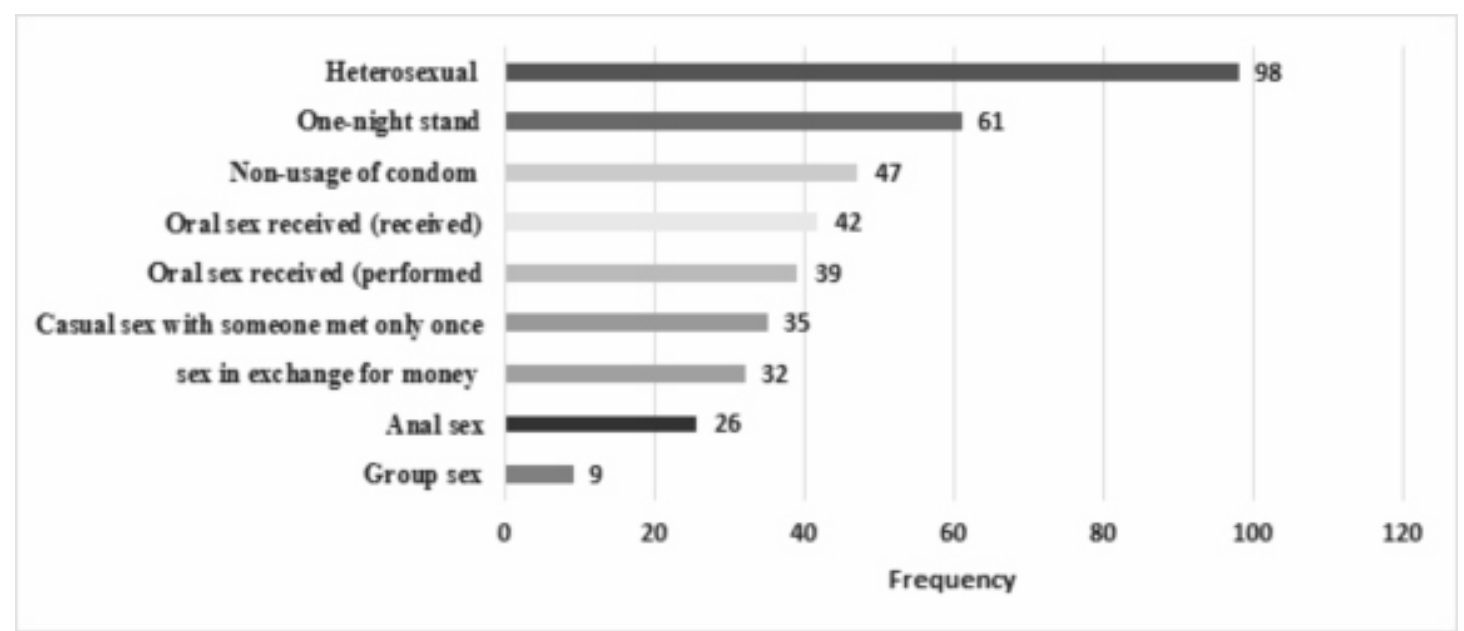

Multiple responses

Figure 1: Sexual risk taking behaviour practiced by respondents who had sex within a week before study 
Table 3: Relationship between sexual risk taking behaviours and alcohol intake among respondents

\begin{tabular}{|c|c|c|c|c|c|c|}
\hline $\begin{array}{l}\text { Sexual risk taking } \\
\text { behavio ur }\end{array}$ & $\begin{array}{l}\text { Total } \\
\text { n (\%) }\end{array}$ & $\begin{array}{l}\text { Take } \\
\text { alcohol } \\
\text { n (\%) }\end{array}$ & $\begin{array}{l}\text { Do not } \\
\text { take } \\
\text { alcohol } \\
\text { n (\%) }\end{array}$ & $\begin{array}{l}\text { Adjusted } \\
\text { OR }\end{array}$ & $\begin{array}{l}95 \% \\
\text { Confidence } \\
\text { Interval }\end{array}$ & $\overline{\mathrm{p} \text {-value }}$ \\
\hline Anal sex & $26(26.5)$ & $23(88.5)$ & $3(11.5)$ & 8.464 & $2.919-24.53$ & 0.0433 \\
\hline Group sex & $9(9.2)$ & $8(88.9)$ & $1(11.1)$ & 2.889 & $0.3795-21.99$ & 0.2727 \\
\hline Heterosexual & $98(100.0)$ & $72(73.5)$ & $26(26.5)$ & 1.616 & $0.648-4.007$ & 0.0000 * \\
\hline One night stand & $61(62.2)$ & $47(77.0)$ & $14(23.0)$ & 1.212 & $0.8178-1.797$ & 0.3045 \\
\hline $\begin{array}{l}\text { Sex in exchange for gifts } \\
\text { or money }\end{array}$ & $32(32.7)$ & $20(62.5)$ & $12(37.5)$ & 0.6019 & $0.3446-1.051$ & 0.0867 \\
\hline $\begin{array}{l}\text { Casual sex with someone } \\
\text { met only once }\end{array}$ & $35(35.7)$ & $21(60.0)$ & $14(40.0)$ & 0.5417 & $0.3265-.8986$ & 0.0243 * \\
\hline Non-usage of condom & $47(48.0)$ & $28(59.6)$ & $19(40.4)$ & 0.5322 & $\begin{array}{l}0.3669 \\
0.7718\end{array}$ & $-0.0027^{*}$ \\
\hline Oral sex(performed) & $39(39.8)$ & $23(59.0)$ & $16(41.0)$ & 0.5191 & $0.3297-.8173$ & $0.0082 *$ \\
\hline Oral sex (Received) & $42(42.6)$ & $24(57.1)$ & $18(42.9)$ & 0.4815 & $\begin{array}{l}0.3179- \\
0.7293\end{array}$ & $0.0015^{*}$ \\
\hline
\end{tabular}

* Pearson chi-square is significant at the 0.05 level (2-tailed)

\section{Discussion}

The socio-demographic characteristics of the respondents in our study are in line with risk factors of reproductive health challenges. Majority of the young people are males and more than two third were singles. This implies that the alcoholic beverage selling points are predominantly patronized by unmarried young persons. School enrolment among the young people in this study was good as majority had either primary, secondary or tertiary education. However, $16.8 \%$ were school drop outs. This condition can predispose young people to engage in crime and other social vices such as armed robbery, and prostitution which has been documented in some studies. ${ }^{17}$

In our study majority of the young people became sexually active during adolescence (mean age of first sexual debut was $18.2 \pm 3.0$ years). This finding is similar to the national average, but the gender differences in our study is at variance with the national values of 17.2 years for males and 21.7 years for female respectively. ${ }^{2}$ On the other hand, the findings in our study is higher than the 11.7 years reported from a study conducted among secondary school students in Idoekiti, Nigeria. ${ }^{18}$ Even though the group in our study commenced sexual activity at an age when they could take informed decision about their lives, if they are not properly educated on the dangers associated with sexual activities, majority of them will come up with several complications in adulthood.

Limiting the number of sexual partners and practicing protected sex are crucial in the fight against the spread of sexually transmitted infections, including HIV. In our study, majority of the young people had multiple lifetime sexual partners. This was higher than the $33 \%$ report to have multiple sexual partners in studies conducted among young adults in an urban community in south-south Nigeria. ${ }^{19}$ The high sexual activity among the young people corroborates the finding in previous 
studies worldwide. ${ }^{20-25}$ The result of this study further confirms the assertion that young people usually take advantage of freedom from direct parental supervision to engage in various social activities which usually make them to engage in sex early. ${ }^{21}$ Regarding the intake of alcohol, majority of young people in our study took alcohol and more males than females took alcohol. This is consistent with other studies where male involvement has been found to be higher. ${ }^{22-24}$ However, our finding is at variance with that from a study conducted in Italy where more females were found to take alcohol compared to the males. ${ }^{25}$ Despite the gender differences, the male and female involvement in our study could be in line with the general belief that alcohol forms an integral part of most human cultures. ${ }^{6-8,23-25}$ The early drinking habit established in our study shows the likelihood of future alcohol dependence or abuse in adulthood if not controlled. The cumulative effect of the alcoholic intake may be the probable reason behind the multiple sexual relationship demonstrated in our study. Therefore, addressing these issues would assist in scaling down risky sexual practices, unsafe sexual behaviours and HIV infection through sexual intercourse.

In our study, even though young people became sexually active during adolescence, the use of condoms during sexual intercourse was low. The result of our finding is probably the reason why young adults have been reported to have contributed to high burden of sexually transmitted infections and unsafe abortions globally. ${ }^{11}$ From the logistic regression analysis, young people who take alcohol have greater tendency of engaging in anal sex, sex in exchange for money, casual sex, non-use of condom and oral sex. The strong association between alcohol intake and risky sexual practice in this study is in support of reports by other authors that intake of alcohol is among major drivers of HIV infection in Benue state. ${ }^{9,10}$. Inadequacy or lack of sex and reproductive health education in schools and at home may be responsible for this. Targeted health education campaigns including increasing access to condoms should be intensified for youths.

\section{Conclusion}

Intake of alcohol before sexual intercourse among young people who patronize night clubs and alcohol beverage selling points in Makurdi, Benue State was high and that corroborate the practice of anal sex among them. It was concluded that policymakers working on HIV intervention should consider nightclubs and other drinking establishments catering for young people in order to reduce high risk sexual behaviour and mitigate the effects of disases transmitted through risky sexual behaviour among this population.

One of the major limitation of this study is the interviewer administered questionnaire used for data collection. Some sensitive questions might not have been responded to with the honesty that was desired. There is a tendency to under report risky behaviour. An exploratory component would have helped us to understand more about the context and bring up issues that were not considered. Application of focus group and key informant interviews should be considered in future studies on this subject matter among young adults. Another limitation is the certainty of the age. Young people in this study were regarded as those between 10-24 years old, but the age description was only based on what the respondents gave to the interviewers. However, some historic events in the country and school age history were used as checks to ascertain the age of the respondents.

\section{Acknowledgement}

We sincerely want to thank all the 
participants who took part in the study.

\section{Conflicts of Interest}

There are no conflicts of interest.

\section{References}

1. United Nations, Department of Economic and Social Affairs, Population Division. World Population Prospects: The 2015 Revision, Methodology of the United Nations Population Estimates and Projections, Working Paper. 2015; No. ESA/P/WP. 242.

2. National Population Commission, Nigeria and ICF. Nigeria Demographic and Health Survey 2018 Key Indicators Report. Abuja, Nigeria, and Rockville, Maryland, USA: NPC and ICF. 2019.

3. World Health Organization. Youth and Health Risks. Sixth-Fourth Health Assembly Provisional Agenda Item WHA64/2011/REC/1. WHO, Geneva. 2011. (Accessed at apps.who.int > pdf_files > WHA64REC1 > A64_REC1-en on $3^{\text {rd }}$ July, 2019).

4. Smriti N, Marfatia YS. Adolescent HIV/AIDS: Issues and challenges. Indian J Sex Transm Dis AIDS. 2010; 31(1): 1-10. George A, George L, Michael M, Wolfgang $\mathrm{H}$.

5. HIV Testing and Risk Perceptions: A Qualitative Analysis of Secondary School Students in Kampala, Uganda. J Public Health Afr. 2017; 8(1): 577-583.

6. World Health Organization. Alcohol, Gender and Drinking Problems: Perspectives from low and Middle Income countries. WHO, Department of Mental Health and Substance Abuse, Geneva. 2009.

7. Francisca C, Jose ML. Alcohol Consumption among Adolescents Implications for Public Health. Chapter 3, David Claborn. Topics in
Public Health. Intech Publishers. 2015, pp.51-76. (accessed at www.intechopen.com > books > topics-in-public-health on 16th April, 2019).

8. World Health Organization. Youth and Health Risks. Sixth-Fourth Health Assembly Provisional Agenda Item WHA64/2011/REC/1. Geneva WHO. 2011. (Accessed at apps.who.int > pdf files > WHA64REC1 > A64 REC1-en on $3^{\text {rd }}$ July, 2019).

9. National Agency for the Control of AIDS. Federal Republic of Nigeria, Global AIDS Response Progress Report, 2014. (Accessed at www.unaids.org, files, NGA_narrative_report_2014 on $23^{\text {rd }}$ March, 2019).

10. Timiun GA, Timothy S. The Role of Drinking Places in Enhancing Risky Sexual Behaviours and the Spread of HIV/AIDS amongst the Tiv People of Benue State, Central Nigeria. Universal Journal of Public Health. 2017; 5(5): 222-230.

11. United Nations AIDS Program. Ending the AIDS epidemic for adolescents, with adolescents. A practical guide to meaningfully engage adolescents in the AIDS response. UNAIDS. 2016 (accessed at www.unaids.org on $12^{\text {th }}$ May, 2019)

12. Federal Ministry of Health, Nigeria. Nigeria HIV/AIDS Indicator and Impact Survey (NAIIS) 2018: Technical Report. Abuja, Nigeria. October 2019.

13. United Nations AIDS Program. Fast track, Ending the AIDS epidemic by 2030. UNAIDS. 2014 (Accessed at $\mathrm{w}$ w w. u n a d s.org, UNAIDS_FastTrack_highlights_en on $6^{\text {th }}$ January, 2019).

14. Viviane DL, Martin S, Ignacio R, Jean AS, Bohdan N, Robert SH, et al 
.Progress Towards the United Nations 90-90-90 and 95-95-95 Targets: The Experience in British Columbia, Canada. J Int AIDS Soc. 2017; 20(3):e25011.

15. National Agency for the Control of AIDS. Revised National HIV and AIDS Strategic Framework 20192021. NACA. 2019

16. Araoye MO. Research Methodology with Statistics for Health and Social Sciences. Nathadex publishers Ilorin, 2004: pp 115- 120

17. Owusu-Boateng W, Acheampong F, Oteng A. The effect of school dropout on the lives of the youth in Akim Tafo community. Global Educational Research Journal. 2015; 3(10): 346369. Kabir AD, Oluwole AB, Lukman OO, Olusegun EE, Lawrence MA, Kayode RA, et al.

18. Early sexual debut: prevalence and risk factors among secondary school students in Ido-ekiti, Ekiti state, South-West Nigeria. Afr Health Sci. 2017; 17(3): 614-622.

19. Okafor KC, Adam VY, Azuike EC. Risky sexual behaviour of Young People in an Urban Community, South-South, Nigeria. Global Journal of Medicine and Public Health, 2018; 7 (4): 1-11.

20. AnnDenise B, Shireen JJ, Iqbal S, Kathryn MY. Sexual relations among young people in developing countries: evidence from WHO case $\begin{array}{llllllll}\mathrm{s} & \mathrm{t} & \mathrm{u} & \mathrm{d} & \mathrm{i} & \mathrm{e} & \mathrm{s}\end{array}$. UNDP/UNFPA/WHO/World Bank Special Programme of Research, Development and Research Training in Human Reproduction, 2001.

21. United States Department of Ed u c a t i o n, Office of Communications and Outreach. Helping Your Child through Early Adolescence Washington, D.C.,
$20005 \quad$ ( A c c e s s e d a t www.ed.gov/parents/academic/help/hyc .html on $15^{\text {th }}$ Februaary, 2019).

22. Bradley TK, Delivette C, Phu T, Matthew B, Roger P. Association between intoxication at last sexual intercourse and unprotected sex among men and women in Uganda. J Infect Dev Ctries 2014; 8(11):14611469.

23. World Health Organization. Alcohol use and sexual risk behaviour: a cross-cultural study in eight countries. WHO Geneva. 2005. ISBN 9241562897 (Accessed at $\mathrm{w} \mathrm{w} \mathrm{w}$. $\mathrm{w} \mathrm{ho}$. $\mathrm{i} \mathrm{n} \mathrm{t}$ alcohol_sexual_risk_crosscultural on $5^{\text {th }}$ August, 2018).

24. Lamyaa BE, Bouchra B, Aboubaker E1-H, Ali O, Abdelhalem M. Prevalence of alcohol consumption and alcohol use disorders among middle and high school students in the province of Khemisset, Morocco: a cross-sectional study, International Journal of Adolescence and Youth. 2020; 25:1, 638-648.

25. Francesco B, Daniele C, Cristina C, Alessandro S, Giulia B, Massimo C. et al. Prevalence and Correlates of Binge Drinking among Young Adults Using Alcohol: A Cross-Sectional Survey. Hindawi Publishing Corporation BioMed Research International Volume 2014, Article I D $930795,7 \mathrm{p}$ a g e s . http://dx.doi.org/10.1155/2014/9307 95. 